\title{
Changes of vegetation and its forces driving in the Aral Sea Basin of Central Asia
}

\author{
Xiangye Zhang, Hailong Liu*, and Hui Chen \\ School of Resources and Environment, University of Electronic Science and Technology of China, Chengdu 611731, China
}

\begin{abstract}
Global change brings great uncertainty to the fragile ecological environment of arid area. In order to understand the driving role of climatic factors and socio-economic activity on changes, the distribution and change of vegetation in the Aral Sea basin were examined using data from remote sensing, population data sets from 2000 to 2015 , transfer matrix, and the centre of gravity model. The salient results of the analysis were as follows. (1) Although the index increased slightly in the past 20 years overall, it fluctuated greatly over that time. From 2000 to 2015, the NDVI decreased in approximately $62 \%$ of the area; increased in 24\%; and remained unchanged in 14\%. (2) From 2000 to 2015, the geographic centre of the area under forest land to the northeast, marking the advancement of urbanization upstream. The geographic centre of grassland moved to the west. (3) The overall impact of precipitation on vegetation was greater than that of temperature. Areas showing a strong correlation were mostly concentrated in forest land; the impact of precipitation on grasslands was weak. (4) The distribution of vegetation was adversely affected by the increase in population and in GDP. The present study is of particular significance to the restoration and reconstruction of the Aral Sea basin ecosystem.
\end{abstract}

\section{Introduction}

As climate change and socio-economic development continue, so does the degradation of ecological environment in arid regions, posing a serious challenge to sustainable development of any society [1]. Vegetation, an important part of terrestrial ecosystems, plays a major role in the circulation of materials and energy flows within the system [2], and changes in vegetation are often used as one of the indicators of the degradation of ecological environment [3], Therefore, analysing the evolution of vegetation and the mechanisms that drive such evolution are crucial to monitoring ecological environments [4].

Climate change has a great impact on the growth of vegetation in arid areas [5], mainly by restricting the availability of wateranalysed the relationship between climate and interannual or seasonal changes with reference to the normalized difference vegetation index (NDVI) in Central Asia from 1982 to 2002 and found annual precipitation, especially that in spring, to be the main limiting factor for the growth of vegetation $[6,7]$. Gessner et al. used NDVI and GPCC Full Data Reanalysis from 1982 to 2006 to analyse the sensitivity of vegetation growth in Central Asia to changes in precipitation and found that nearly $80 \%$ of the regional vegetation was affected by precipitation [8]. Deng et al. used long-term climate and hydrological data to analyse the relationship between the water cycle and climate change and reported that increase in winter temperatures has a more significant effect than annual precipitation on the water cycle; the increase in winter temperatures causes the snow cover to retreat, resulting in a significant decrease in run-off [9]. Morris et al. found in Kyrgyzstan that precipitation has little effect on groundwater recharge, and the reduction in river run-off has exacerbated the degradation of lake ecosystems to some extent [10]. As climate change makes the uneven distribution of water resources in arid regions even more marked, a series of ecological and environmental problems such as degradation of vegetation, salinization of soils, shrinking of lakes, and degradation of entire ecosystems become more prominent $[11,12]$.

Human activities also affect the evolution of vegetation and contribute to the degradation of ecological environment in arid areas [13]. After 1950, as the Central Asian economic system and social pattern began to change, the traditional system for managing water resources was destroyed completely [14]. Water consumption in the regional economy has increased sharply, and many regions have undergone excessive development and have been exploiting natural resources beyond their carrying capacity for a long time [15]. Luo et al. used the Cellular Automata (CA)-Markov model to analyse the spatial and temporal dynamics of the Ili river delta in Kazakhstan and found that lakes, swamps, and other landscapes in the region had been markedly disturbed and that the projects for water conservation had greatly changed the structure of the landscape $[16,17]$. Similarly, Crosa et al. reported that farming had hastened the secondary salinization of soil in the Amu Darya basin, which, in turn, had affected water use in the lower Amur basin [18].

The Aral Sea basin, a typical area in the arid zone,

\footnotetext{
* Corresponding author: liu hai tiger@163.com
} 
has been facing severe ecological and environmental problems in recent years. Water reserves in the basin have been decreasing on average at $0.30-0.42 \mathrm{~cm}$ annually [14]; the area under vegetation that has been degraded in Central Asia increased by $0.58 \times 105 \mathrm{~km}^{2}$ from 1990 to 2005, an average annual increase of 3,937 $\mathrm{km}^{2}$; the area under glaciers in the Tianshan area decreased by $23 \%$ between 1990 and 2005 [19]; and the area covered by lakes decreased by nearly $50 \%$ between 1975 and 2007 [20].

Although researchers have studied changes in water resources and the evolution of vegetation in the Aral Sea basin in recent years, spatial details of the relationship between climate change and the evolution of vegetation and location of the spatial centre of the sweeping ecological degradation have received little attention, so the present paper is one attempt to fill that gap in knowledge. More specifically, the paper (1) analyses the characteristics of spatial distribution of vegetation and changes in the pattern of vegetation in the Aral Sea basin to examine how they have been affected by climate change and human activity and (2) seeks to explain the forces that have been driving those changes.

\section{Data and Methods}

\subsection{Research area}

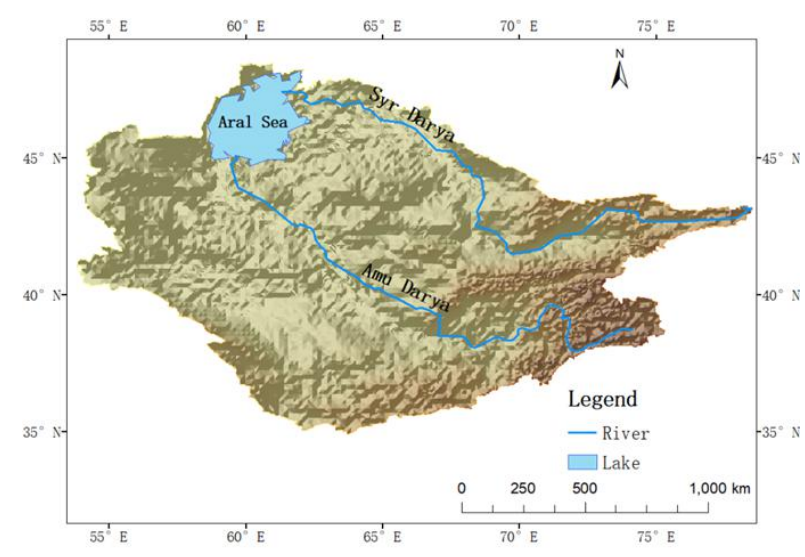

Fig. 1. Aral Sea basin. This figure was drawn using ArcGIS10.1.

The Aral Sea basin was the chosen research area $\left(32.4^{\circ}-\right.$ $48.3^{\circ} \mathrm{N}, 51.8^{\circ}-79.2^{\circ} \mathrm{E}$ ), which is spread over 2.207 million $\mathrm{km}^{2}$ (Fig. 1). The Aral Sea basin includes two major rivers, Amu Darya and the Syr Darya. The terrain is uneven, high to the east and low to the west, and the land form shows abrupt changes. In addition, to the east and the southeast are mountains, valleys, and hills of the Tianshan and Pamir mountains, and to the west is the Turan Plain, consisting mainly of deserts, grasslands, and oases [21]. Lying at the centre of Eurasia, the Aral Sea basin has a typical continental arid and semi-arid climate with an average annual rainfall of less than 300 $\mathrm{mm}$ [22]. The total water resources of the Aral Sea basin are estimated at $1.335 \times 108 \mathrm{~m}^{3}$, and most areas face severe water shortages [15]. The Aral Sea basin comprises desert and semi-desert lands and grassland from the Caspian Sea to the Tianshan Mountains. Roughly three-fourths of the total area of Central Asia is covered with vegetation, consisting of cultivated lands (20.8\%), forest lands (26.2\%), and grasslands (26\%) [23].

\subsection{Sources and pre-processing of data}

The data on vegetation consisted of 16-day MOD13Q1 thematic product synthesis data from 2000 to 2018 from NASA, the US National Aeronautics and Space Administration(https://ladsweb.modaps.eosdis.nasa.gov/ search/order/1/MOD13Q1--6), which uses sinusoidal projection with a spatial resolution of $250 \mathrm{~m} \times 250 \mathrm{~m}$. The MODIS reprojection tool was used first to extract, stitch, and project the NDVI data, and ArcGIS ver. 10.2 was then used for cropping and extracting the maximum value of NDVI in each year to obtain the annual NDVI.

Data on land use were sourced from the Climate Change Initiative (CCI) global land cover products from the European Space Agency (https://www.esalandcover-cci.org). The spatial resolution was $300 \mathrm{~m} \times$ $300 \mathrm{~m}$. The products included 22 types of land types. Because the main types of land in the Aral Sea basin are only six, namely cultivated land, forest land, grassland, bare land, water bodies, and residential land [23], those 22 land types of CCI were resampled into the above six main land types for the purposes of the present study.

Precipitation data were taken from TRMM3B42 daily data from 2000 to 2018, also from NASA (https://disc.gsfc.nasa.gov/), and the spatial resolution was $0.25^{\circ} \times 0.25^{\circ}$. In addition, evaporation data comprised 8-day MOD16A1 thematic product synthetic data (https://ladsweb.modaps.eosdis.nasa.gov) at a spatial resolution of $500 \mathrm{~m} \times 500 \mathrm{~m}$. Temperature data for the same period were reanalysed by the European Centre for medium-term weather forecasts (https://cds.climate.copernicus.eu) and the spatial resolution was $0.25^{\circ} \times 0.25^{\circ}$. The annual cumulative precipitation, evaporation and average temperature on the 16th were calculated using ArcGIS 10.2.

Data on GDP and population of the countries in the Aral Sea basin during 2000-2018 were taken from the Food and Agriculture Organization (www.fao.org), and the area weight method was used for calculating the GDP and the total population of the Aral Sea basin.

\subsection{Rate of change in vegetation}

The rate of change of vegetation over the study area and during the study period was calculated using the formula (1):

$$
K_{T}=\frac{U_{a}-U_{b}}{U_{a}} \times \frac{1}{T} \times 100 \%
$$

where $\mathrm{K}_{\mathrm{T}}$ is the rate of change of vegetation during the study period; $\mathrm{U}_{\mathrm{a}}$ and $\mathrm{U}_{\mathrm{b}}$ are the areas under a given vegetation type at the beginning and at end of the study period, respectively; and $\mathrm{T}$ is the duration of the study. When set to $\mathrm{N}$ years, the model results indicate annual rate of change of the given vegetation type in the district over this period [24].

\subsection{Spatial distribution of centres of vegetation}

The spatial centre of an area under a given type of vegetation can reflect the spatial concentration of 
vegetation types. The characteristic spatial distribution of different vegetation types was analysed by comparing the location of the centre at the beginning of the study period to that at the end of the study period. The following two formulae were used for the calculations [25]:

$$
\begin{gathered}
X_{j}(t)=\frac{\sum_{i=1}^{N_{j}(t)}\left(C_{i j}(t) \times X_{i j}(t)\right)}{\sum_{i j}^{N_{j}(t)} C_{i j}(t)} \\
Y_{j}(t)=\frac{\sum_{i=1}^{N_{j}(t)}\left(C_{i j}(t) \times Y_{i j}(t)\right)}{\sum_{i=1}^{N_{j}(t)} C_{i j}(t)}
\end{gathered}
$$

In the above formulae, $\mathrm{X}_{j}(\mathrm{t})$ and $\mathrm{Y}_{\mathrm{j}}(\mathrm{t})$ are the coordinates of the spatial centre of vegetation type $j ; t$ is a time variable; $\mathrm{N}_{\mathrm{j}}(\mathrm{t})$ is the number of patches of vegetation type $\mathrm{j} ; \mathrm{C}_{\mathrm{ij}}(\mathrm{t})$ is the ith patch area of vegetation type $j$; and $\mathrm{X}_{\mathrm{ij}}(\mathrm{t})$ and $\mathrm{Y}_{\mathrm{ij}}(\mathrm{t})$ are, respectively, the latitude and longitude of the geometric centre of the ith patch of vegetation type $\mathrm{j}$.

\subsection{Changes in land use}

Transfer matrix analysis is a quantitative description of the system state and state transition in system analysis and can express comprehensively and specifically the structural characteristics and directions of various dynamic changes in land use. We obtained data on land use in the Aral Sea basin for 2000, 2007, and 2015 through pre-processing. Data on land use were analysed by calculating the transfer matrix from 2000 to 2007 and from 2007 to 2015, using the following formula [26]:

$$
P=\left[\begin{array}{cccc}
P_{11} & P_{12} & \cdots & P_{1 n} \\
P_{21} & P_{22} & \cdots & P_{2 n} \\
\cdots & \cdots & \cdots & \cdots \\
P_{n 1} & P_{n 2} & \cdots & P_{n n}
\end{array}\right]
$$

where $P_{i j}$ is the ratio of the area of land use type converted from type $i$ to type $j$ to the total land area from 2000 to 2007 or 2007 to 2015 , and P is the ratio of the area of the land use type that has always been type i to the total land area from 2000 to 2007 or from 2007 to 2015.

\subsection{Changes in land use}

Spatial correlation analysis method was introduced to analyze the correlation between NDVI changes and meteorological factors[27]. The strength of the correlation was defined based on correlation coefficient $(\mathrm{r})$ as follows: $-1.0 \leq \mathrm{r}<-0.6$, strong negative correlation; $-0.6 \leq \mathrm{r}<0$, weak negative correlation; $\mathrm{r}=0$, no correlation; $0<\mathrm{r}<0.6$, weak positive correlation; and more than $0.6 \leq$ $\mathrm{r} \leq 1.0$, strong positive correlation.

In addition, anomaly analysis method is introduced to distinguish the change direction and intensity of meteorological factors [28].

\section{Results Analysis and Discussion}

\subsection{Evolution of vegetation}

\subsubsection{Spatial and temporal distribution of vegetation}

To understand the distribution of vegetation in the Aral Sea basin since 2000, the data on land use were reclassified into forest land and grassland, uses that are closely related to the distribution, whereas the remaining land-use types were combined into a single category, namely 'other land uses'. To reflect the growth of vegetation, forest land and grassland were each further divided into those in which $50 \%$ or more of the area was covered and those in which the cover was less than 50\% (Fig. 2).
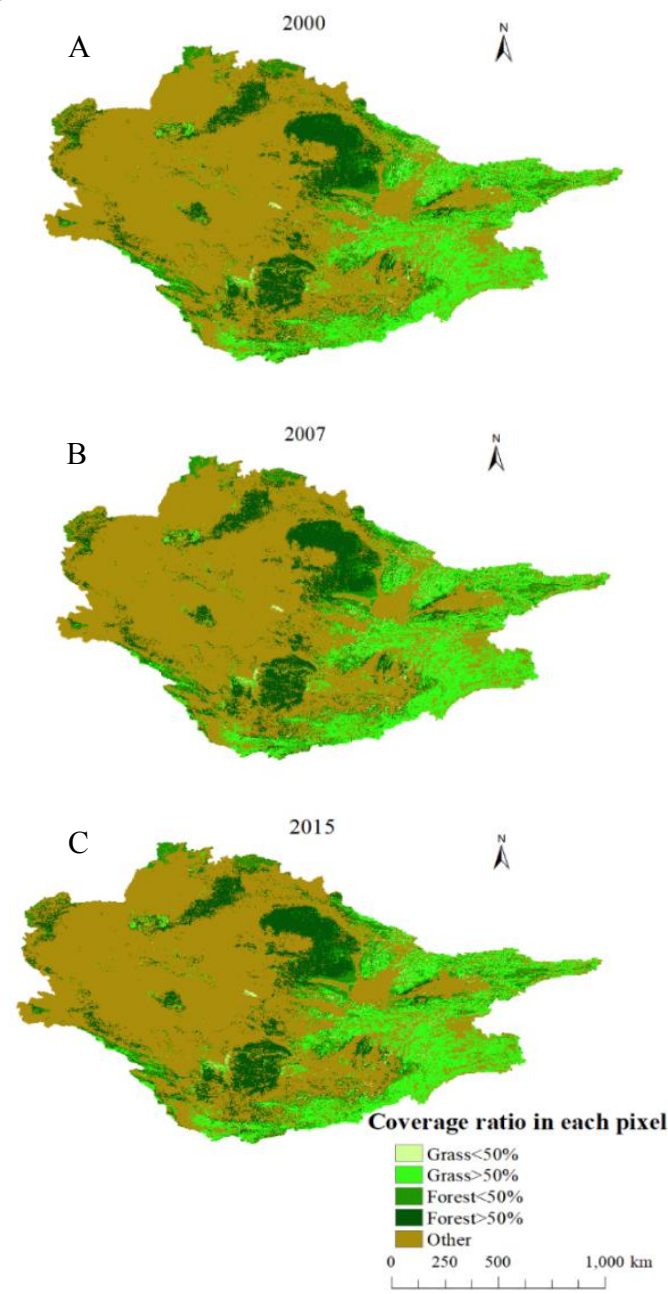

Fig. 2. Distribution of vegetation in Aral Sea basin from 2000 to 2015. These figures were drawn using ArcGIS10.1.

Fig. 2 shows that the area under vegetation, mainly to the east and north, accounts for less than half, slightly over one-third, of the total area of the Aral Sea basin. The distribution of grasslands is more concentrated, and they are found mainly in the mountainous parts of the eastern and southern fringes, the Tianshan Mountains, the Pamirs, and the upper reaches of the Syr River. The distribution of forest lands, on the other hand, is more dispersed or sparse, and they are found mainly on the south-eastern and northern plains, between Tamde district of Uzbekistan and Shelly district of Kazakhstan, and in the southern regions of Mare and Lebap. The area around the Aral Sea is a desert. The area under grassland is greater than that under forest land. In 2000, 2007, and 2015 , more than $16 \%$ of the area was under grassland that belonged to the first category mentioned above (cover greater than 50\%), and the area under the second category was about $1 \%$; the corresponding figures for 
Grass land and forest land were approximately $12 \%$ and $7 \%$.

\subsubsection{Rates of spatial and temporal changes in vegetation}

To analyse the changes in vegetation of the Aral Sea basin over the years, annual changes in the NDVI were noted first (Fig. 3).

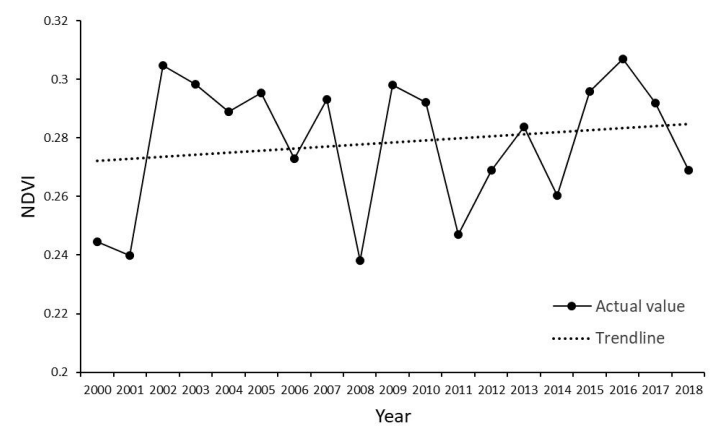

Fig. 3. Annual changes in normalized difference vegetation index (NDVI) in the Aral Sea basin. This figure was prepared by Microsoft Excel (OFFICE 2010).

Fig. 3 shows that the annual average NDVI in the Aral Sea basin was $0.24-0.31$, which is low. Although the index increased slightly in the past 20 years, it fluctuated widely, pointing to the fragility of vegetation in the basin. The lowest value was in 2008 and the highest, in 2016; currently the trend is of a slow increase.

The index was also used to calculate the rate of change between 2000 and 2018 (Fig. 4).

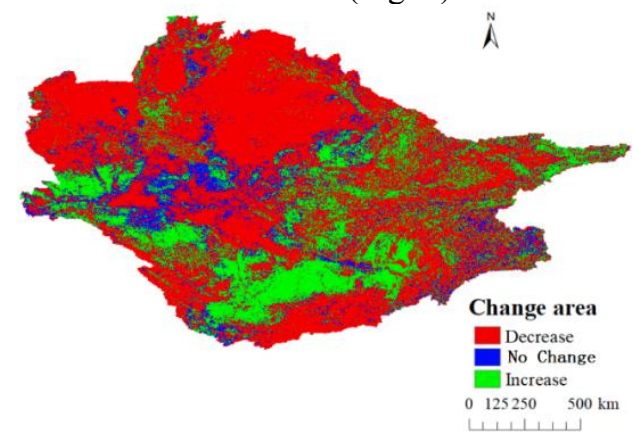

Fig. 4. Rate of spatial change in vegetation in the Aral Sea basin from 2000 to 2018 . This figure was drawn using ArcGIS10.1.
Fig. 4 indicates that from 2000 to 2018, the area under vegetation increased, but the density of cover decreased. Further analysis showed that the area with decreasing NDVI accounted for approximately $62 \%$ of total, that with increasing NDVI accounted for approximately $24 \%$, and that with unchanged NDVI, for approximately $14 \%$. On the other hand, in terms of land use, forest land increased by $0.94 \%$ during 2000-2007 and by $0.15 \%$ during $2007-2018$ and grassland, by $0.34 \%$ and $0.10 \%$, respectively. On the other hand, the area under water bodies decreased by approximately $23 \%$ and $14 \%$ and residential areas increased by approximately $182.5 \%$ and $54.5 \%$, respectively, during the two periods.

Next, the NDVI was examined for different types of land use. The average annual NDVI in each type of land use was 0.2546-0.4992. In descending order of the index, the land-use types were cultivated land, residential area, grassland, and forest land. The overall trend was of increase in the NDVI before 2007 and a decrease thereafter. The magnitude of change in the index was the highest in forest land, followed by grassland, which yet again underscores the fact that natural vegetation in the basin is fragile.

\subsection{Evolution of vegetation}

Spatial changes in vegetation in the Aral Sea basin were analysed mainly through the transfer matrix and by tracking changes in the location of the centre of each vegetation type.

\subsubsection{Transfer matrix of vegetation types}

The data on land use for 2000, 2007, and 2015 were reclassified into the following six types using the method of transfer matrix analysis: evergreen coniferous forest (ECF), deciduous broad leaf forest (DBF), deciduous coniferous forest (DCF), Bush Forest (BF), sparse woodland (SW), high grass cover (HGC), middle and low grass cover (MLGC), Others(OT). Next, the patterns of transfer from one type into a different type were examined for two periods, namely 2000-2007 (Table 1) and 2007-2015 (Table 2).

Table 1. Transfers between vegetation types in the Aral Sea basin: 2000-2007 (\%)

\begin{tabular}{|c|c|c|c|c|c|c|c|c|c|c|}
\hline \multicolumn{11}{|c|}{2007} \\
\hline \multirow{9}{*}{2000} & & DBF & ECF & DCF & $\mathrm{BF}$ & SW & HGC & MLGC & OT & Total \\
\hline & DBF & 99.7997 & 0 & 0 & 0 & 0 & 0 & 0.0223 & 0.1780 & 100 \\
\hline & ECF & 0 & 89.4923 & 0 & 0.7602 & 0.3102 & 1.8178 & 3.9661 & 3.6534 & 100 \\
\hline & DCF & 0 & 0 & 99.5534 & 0.0354 & 0 & 0.2545 & 0.1079 & 0.0489 & 100 \\
\hline & $\mathrm{BF}$ & 0 & 0 & 0 & 99.9866 & 0 & 0.0004 & 0.0048 & 0.0081 & 100 \\
\hline & SW & 0.0006 & 0.0004 & 0.0001 & 0.0010 & 97.8441 & 0.0008 & 0.6322 & 1.5209 & 100 \\
\hline & HGC & 0.0164 & 0.7976 & 1.9196 & 0.9791 & 0.0059 & 88.7579 & 0 & 7.5237 & 100 \\
\hline & MLGC & 0.0025 & 0.0083 & 0.0116 & 0.0126 & 0.1334 & 0 & 98.7980 & 1.0337 & 100 \\
\hline & OT & 0.0009 & 0.0011 & 0.0034 & 0.0029 & 0.1952 & 0.0006 & 0.1346 & 99.6613 & 100 \\
\hline
\end{tabular}


Table 2. Transfers between vegetation types in the Aral Sea basin: 2007-2015 (\%)

\begin{tabular}{|c|c|c|c|c|c|c|c|c|c|c|}
\hline \multicolumn{11}{|c|}{2015} \\
\hline \multirow{9}{*}{2007} & & DBF & ECF & DCF & $\mathrm{BF}$ & SW & HGC & MLGC & OT & Total \\
\hline & DBF & 96.3526 & 0 & 0 & 0.0638 & 0 & 0.0106 & 0.5211 & 3.0519 & 100 \\
\hline & ECF & 0 & 90.9230 & 0 & 1.0478 & 0.0055 & 1.5402 & 2.7630 & 3.7205 & 100 \\
\hline & DCF & 0 & 0 & 97.0155 & 0.7851 & 0 & 0.6518 & 0.6101 & 0.9376 & 100 \\
\hline & $\mathrm{BF}$ & 0.0004 & 0.0014 & 0.0021 & 99.9260 & 0.0001 & 0.0035 & 0.0231 & 0.0434 & 100 \\
\hline & SW & 0.0010 & 0 & 0 & 0.0001 & 98.5371 & 0.0004 & 0.9648 & 0.4965 & 100 \\
\hline & HGC & 0.0078 & 0.2120 & 0.3486 & 0.3030 & 0.0013 & 92.5409 & 0 & 6.5864 & 100 \\
\hline & MLGC & 0.0078 & 0.0089 & 0.0075 & 0.0094 & 0.1664 & 0 & 99.0423 & 0.7577 & 100 \\
\hline & OT & 0.0009 & 0.0006 & 0.0006 & 0.0012 & 0.0790 & 0.0003 & 0.0621 & 99.8552 & 100 \\
\hline
\end{tabular}

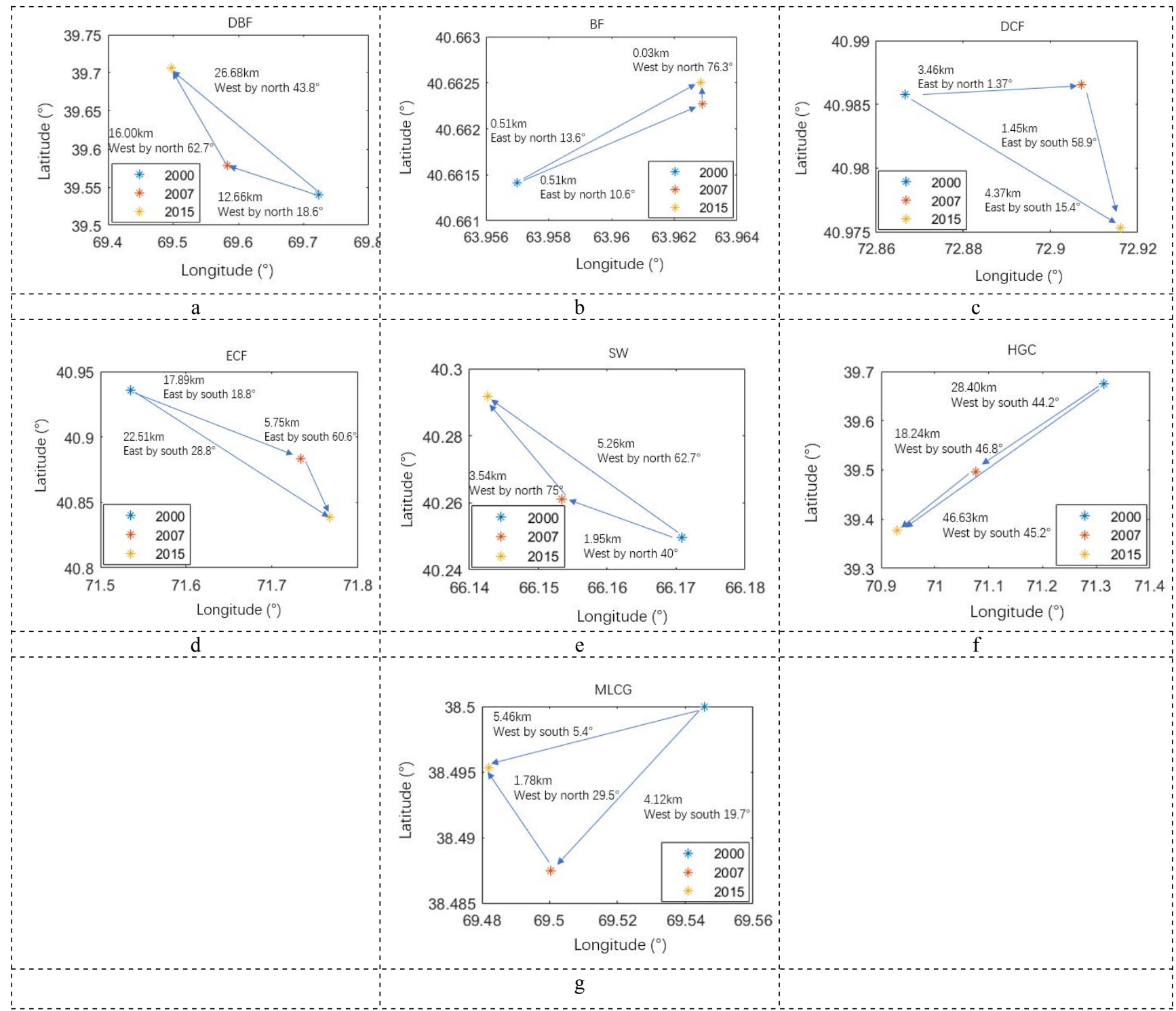

Fig. 5. Rate of spatial change in vegetation in the Aral Sea basin from 2000 to 2018. This figure was drawn using ArcGIS10.1.

Table 1 show that transfers of land parcels between different vegetation types were limited during 20002007. As a result of such transfer, the area under HGC increased by $0.0106 \%$; that under MLGC, by $0.5211 \%$. On the other hand, the area under BF decreased by $0.0048 \%$ and that under SW, by $0.6322 \%$. The gains in the area under HGC and MLGC were mostly at the cost of that under forest land. SW suffered the greatest loss, and the lost area was converted into MLGC, a pattern that clearly showed that the lopsided spatial distribution of water resources and decrease in the area under water bodies and thus the inevitable degradation of the ecological environment. In addition, the area under HGC decreased by $7.5237 \%$. The lost area was converted into 
the OT type, which indicated that vegetation is degenerating.

The pattern of transfer during 2007-2015 (Table 2) was similar to that during 2000-2007, but the magnitude of fluctuations decreased slightly. The area under HGC increased by $1.5402 \%$; that under MLGC, by $2.7630 \%$. The area under BF and SW decreased slightly, by $0.0231 \%$ and $0.9648 \%$, respectively. The gain in HGC came mainly from the loss in forest land, and that in MLGC, from the loss in forest land, BF and SW. As during the earlier period, the area under all types was diverted to OT type, the degradation of the ecological environment was thus continued.

\subsubsection{Changes in centres of vegetation types and their spatial distribution}

The geographic centre of a vegetation type reflects the increase and decrease in land under a given vegetation type in all directions of the compass. If vegetation type increases or decreases evenly over a study area, the centre remains mostly unchanged; if the changes are uneven, the centre moves (Zhang et al. 2014). In order to analyse the dynamics of changes in vegetation type in the Aral Sea basin, we mapped the centres of different vegetation types and examined changes in the locations of those centres during 2000-2007 and 2007-2015 (Fig. $5)$.

Table 3. Correlation between NDVI and climate factor in different forest types

\begin{tabular}{|c|c|c|c|}
\hline Vegetation Type & Temperature $\left(\mathrm{R}_{\mathrm{T}}\right)$ & Precipitation $\left(\mathrm{R}_{\mathrm{P}}\right)$ & Evaporation $\left(\mathrm{R}_{\mathrm{ET}}\right)$ \\
\hline DBF & 0.5351 & 0.5128 & 0.3891 \\
\hline ECF & 0.5432 & 0.2886 & 0.4942 \\
\hline DCF & 0.5233 & 0.0148 & 0.3251 \\
\hline BF & 0.2249 & 0.7266 & 0.1658 \\
\hline SW & 0.2564 & 0.7120 & 0.1198 \\
\hline HGC & 0.1300 & 0.6130 & 0.5188 \\
\hline MLGC & 0.1106 & 0.6862 & 0.1754 \\
\hline Overall & 0.1502 & 0.7400 & 0.2126 \\
\hline
\end{tabular}

Table 3 shows that the overall correlation coefficient between precipitation and NDVI is 0.74 , which is larger than that between temperature and NDVI or between evaporation and NDVI. Specifically, the correlation between temperature and NDVI in forest types is larger than in other types; the correlation between precipitation and NDVI in bush, woodland or grassland is larger than in other types; the correlation between evaporation and NDVI in HGC is larger than other types. All precipitation, temperature and evaporation were significantly correlated to the NDVI.

Next, the spatial correlation was estimated. The spatial correlations with temperature and precipitation are shown in Fig. 6: data on evaporation are not shown because the values were not available for many locations in the desert area.

Overall, temperature (Fig. 6a) was weakly correlated to the NDVI, the area showing positive correlation being larger than that showing negative correlation. The area
Fig. 5 shows that the centres of BF, ECF, and DCF moved eastwards whereas those of DBF, SW and grass land moved westwards. The most marked changes in the location were seen with the degradation of the ecological environment. Between 2000 and 2015, the geographic centre of the area under ECF moved $22.51 \mathrm{~km}$ to the southeast and that of the area under BF moved $0.51 \mathrm{~km}$ to the northeast, marking the advancement of urbanization upstream, a march that also affected water resources. The geographic centre of HGC moved 46.63 $\mathrm{km}$ to the southwest, and that of SW, $5.62 \mathrm{~km}$ to the north-west, revealing the dwindling water resources and the degradation of forest land upstream of the river. The degradation of forest land into grassland and of other types of land into bare land and thus the degradation of the ecological environment in the lower reaches of the river basin.

\subsection{Forces driving the evolution of vegetation}

\subsubsection{Impact of climate on vegetation}

(1) Correlation between NDVI and climate factor Using the method described above, we analysed the NDVI data from 2000 to 2015 and the corresponding data on temperature, precipitation, and evaporation (Table 3). showing a strong positive correlation accounted for only $0.27 \%$ of the total; that with a weak positive correlation accounted for $80.95 \%$; and that with a weak negative correlation accounted for the rest $18.78 \%$. Areas with a positive correlation were concentrated mainly to the north, centre, and east, whereas those with a negative correlation were concentrated to the south and southeast. Generally, areas with more vegetation showed a more positive correlation between temperature and the NDVI.

Similarly, precipitation (Fig. 6b) also showed an overall positive correlation to the NDVI. The area showing a strong positive correlation accounted for $12.03 \%$ of the total; that with a weak positive correlation, $73.72 \%$; that with a strong negative correlation, $0.17 \%$; that with a weak negative correlation, $14.04 \%$; and that showing no correlation, $0.04 \%$. In general, the impact of precipitation on the NDVI was mostly negative in the eastern mountainous areas and in areas occupied by water bodies, whereas in most other areas, the impact 
was positive.
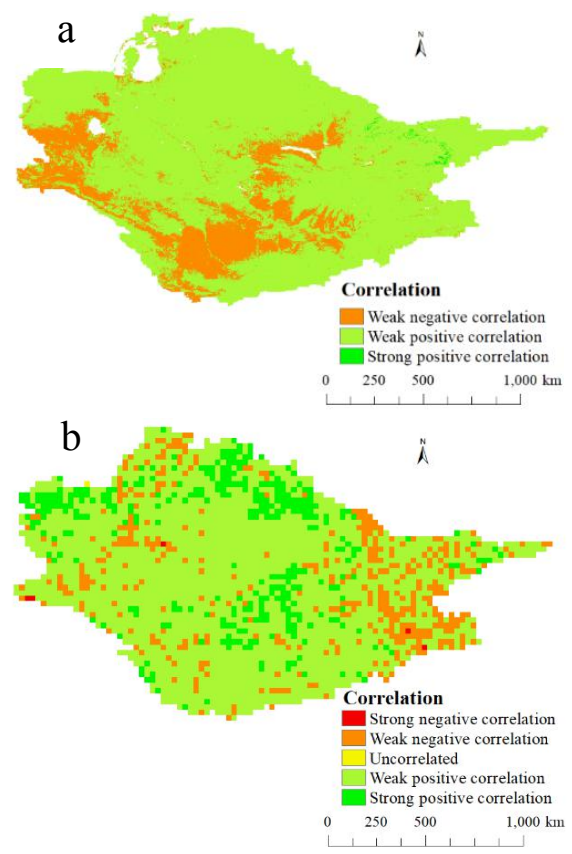

Fig. 6. Spatial correlation between normalized difference vegetation index (NDVI) and temperature (a) or precipitation (b). These figures were drawn using ArcGIS10.1.

(2) Response of vegetation to climate change In order to analyze the response relationship between vegetation and climate change, the vegetation change map was obtained through overlaying vegetation distribution map in 2000 and 2015. Meanwhile, the precipitation and temperature anomalies from 2000 to 2015 were calculated (Fig. 7).

Fig. 7 (a) shows that the vegetation area in the Aral Sea basin is slightly larger than one third of the total area. During the period of 2000-2015, the vegetation change areas were mainly distributed in the northern, eastern, southern mountainous areas and around the Aral Sea. The changing vegetation types included $\mathrm{BF}, \mathrm{SW}$ and MLGC. Fig. 7 (b) indicates that precipitation increased weakly in most areas of the Aral Sea basin, while the areas of decreased are concentrated in the eastern part of the Aral Sea basin. Fig. 7 (c) shows that temperature increased in most of the areas, and only a small part of southeast area have a slight decrease
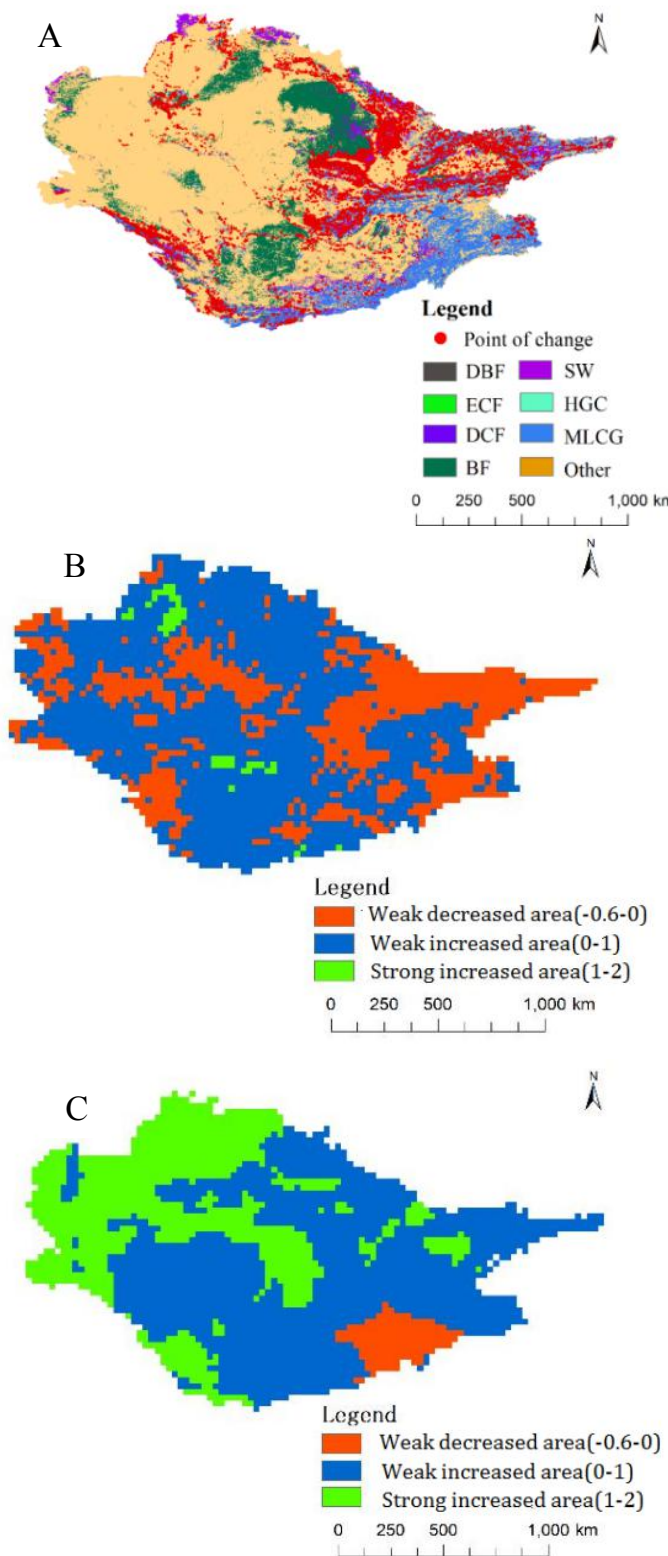

c

Fig. 7. Variation of vegetation, precipitation and temperature during 2000-2015 (a vegetation change; b Precipitation anomaly; $\mathrm{c}$ temperature anomaly). These figures were drawn using ArcGIS10.1.

Table 4. Distribution of vegetation in different fluctuation of climatic factors

\begin{tabular}{|c|c|c|c|c|c|c|}
\hline $\begin{array}{c}\text { Percentage of } \\
\text { area (\%) }\end{array}$ & \multicolumn{3}{|c|}{ Temperature anomaly } & \multicolumn{3}{c|}{ Precipitation anomaly } \\
\hline & $\begin{array}{c}\text { Weak decreased } \\
\text { area (-0.002-0) }\end{array}$ & $\begin{array}{c}\text { Weak increased } \\
\text { area (0-0.004) }\end{array}$ & $\begin{array}{c}\text { Strong increased } \\
\text { area (0.004-0.0082) }\end{array}$ & $\begin{array}{c}\text { Weak decreased } \\
\text { area (-0.6-0) }\end{array}$ & $\begin{array}{c}\text { Weak increased } \\
\text { area (0-1) }\end{array}$ & $\begin{array}{c}\text { Strong increased } \\
\text { area }(1-2)\end{array}$ \\
\hline DBF & 0 & 80 & 20 & 60 & 40 & 0 \\
\hline ECF & 0 & 100 & 0 & 0 & 100 & 0 \\
\hline DCF & 0 & 83.33 & 16.67 & 100 & 0 & 0 \\
\hline BF & 1.91 & 65.57 & 32.52 & 16.27 & 82.13 & 1.6 \\
\hline SW & 5.97 & 72.64 & 21.39 & 40.19 & 59.81 & 0 \\
\hline HGC & 20 & 80 & 0 & 66.67 & 33.33 & 0 \\
\hline MLGC & 13.38 & 75.51 & 11.11 & 47.33 & 52.18 & 0.49 \\
\hline
\end{tabular}


As shown in Table 4, vegetation was mainly concentrated in the areas with temperature increased, and only a small part of vegetation was distributed in the areas with temperature decreased. Specifically, almost all of the forest land was distributed in the area with temperature increased, and less than $20 \%$ of the grassland was distributed in the area with temperature decreased. In terms of precipitation, there were little vegetation in all areas with strong precipitation increased, mainly concentrated in areas with weak decrease and weak increase. All ECF was distributed in the increased area. DCF was in the decreased area. The rest were roughly equal in the two types.

In summary, the overall impact of precipitation on vegetation was greater than that of temperature. Precipitation also impacted the extent of vegetation cover, and the greater the NDVI, the stronger the correlation. Areas showing a strong correlation were mostly concentrated in forest land; the impact of precipitation on grasslands was weak. Further analysis also revealed a parabolic relationship between temperature and the NDVI. When the temperature of the Aral Sea basin was average $\left(15-16.3^{\circ} \mathrm{C}\right)$, the NDVI increased with increase in temperature; at somewhat higher temperatures $\left(16.3-17.5^{\circ} \mathrm{C}\right)$, the index decreases with increase in temperature. The influence of precipitation is larger when the precipitation was 160 $285 \mathrm{~mm}$. In addition, the typical threshold of evaporation was $40 \mathrm{~mm}$ : when it was less than $40 \mathrm{~mm}$, the NDVI decreased with increase in evaporation; when the evaporation was between $40 \mathrm{~mm}$ and $90 \mathrm{~mm}$, the NDVI increased with increase in evaporation.

\subsubsection{Impact of human activity on vegetation}

Human activity can also affect the distribution and circulation of water resources, which, in turn, affects the distribution of vegetation and its growth. For analysing the impacts of human activity, the GDP and population in the basin were used as proxies. Compared to that in 2000, the GDP of the Aral Sea basin increased by USD 137.7 billion in 2015 and the total population increased by 15.1 million. The analysis in Section 3.2 shows that urbanization of the Aral Sea basin continued to expand since 2000: urbanized area is now spread over $5930 \mathrm{~km}^{2}$, and the area under bare land increased by about 14470 $\mathrm{km}^{2}$. The correlation between the NDVI and the GDP or the population of seven countries in the Aral Sea was examined for the period 2000-2015 (Table 5).

Table 5. Correlation between normalized difference vegetation index (NDVI) and GDP or population of seven countries in the Aral Sea basin (2000-2015).

\begin{tabular}{|c|c|c|c|c|}
\hline \multirow{2}{*}{ Country } & \multicolumn{2}{|c|}{ Natural vegetation changes $\left(\mathrm{km}^{2}\right)$} & \multirow{2}{*}{$\begin{array}{l}\text { Correlatio } \\
\mathrm{n} \text { to GDP }\end{array}$} & \multirow{2}{*}{$\begin{array}{c}\text { Correlation to } \\
\text { population }\end{array}$} \\
\hline & 2000-2007 & $2007-2015$ & & \\
\hline Afghanistan & 1111.55 & -87.1098 & -0.0490 & -0.1205 \\
\hline Pakistan & 117.3463 & 256.92 & -0.1176 & -0.0617 \\
\hline Kazakhstan & 557.935 & 1210.089 & -0.2427 & -0.1089 \\
\hline Kyrgyzstan & -758.162 & -578.993 & -0.2386 & -0.0681 \\
\hline Tajikistan & 159.9114 & -387.495 & -0.1993 & -0.0913 \\
\hline Turkmenistan & 578.0026 & -34.106 & -0.1957 & -0.0888 \\
\hline Uzbekistan & 3114.267 & 496.6521 & -0.1529 & -0.1078 \\
\hline
\end{tabular}

Table 5 indicates that the extent of vegetation increased in all countries except Kyrgyzstan, which showed a decrease of about $760 \mathrm{~km}^{2}$ between 2000 and 2007. The largest increase (about $3115 \mathrm{~km}^{2}$ ) was in Uzbekistan. The pattern was more or less the same during 2007-2015: Kyrgyzstan recorded a decrease of about $580 \mathrm{~km}^{2}$ whereas the maximum increase (1210 $\mathrm{km}^{2}$ ) was seen in Kazakhstan.

Population growth and increased GDP both had a negative impact on vegetation; in other words, socioeconomic development can lead to the deterioration of the ecological environment. However, the correlation was very weak. Also, population and GDP are somewhat broad parameters, and a country is too large a unit for such analyses: more detailed analyses at higher spatial resolutions (county) will be carried out in the future.

\section{Conclusions}

Based on the data from 2000 to 2015 on land use and extent of vegetation in the Aral Sea basin, the forces that drove the distribution and evolution vegetation were analysed, supplemented with data on population and GDP of seven countries in the region to assess the impact of socio-economic development on the ecological environment. The main conclusions from the study are presented and briefly discussed here.

(1) Over the past 20 years or so, the NDVI in the Aral Sea basin has increased slightly but has also fluctuated widely. Of the total area studied, the NDVI decreased in approximately $62 \%$ of the area; increased in $24 \%$; and remained unchanged in $14 \%$. The area under natural vegetation increased during both the periods: forest land increased by $0.94 \%$ during $2000-2007$ and by $0.15 \%$ during 2007-2015; the corresponding figures for grassland were $0.34 \%$ and $0.10 \%$. It shows that the vegetation distributes unevenly in the Aral Sea basin. Although the NDVI became larger, it cannot prove that the overall ecological environment is getting better. It may be that the good vegetation gets better and the poor vegetation gets worse. 
(2) Between 2000 and 2015, the gains in the area under HGC and MLGC were mostly at the cost of that under forest land. As during the earlier period, the area under all vegetation types was diverted to OT type, the degradation of the ecological environment was thus continued. The reason may be that the forest land with large water demand was influenced by development greater than the grassland. This indicates that is degenerating.

(3) The geographic centres of vegetation moved to the surrounding basin, a pattern that clearly shows the link between increased human activity and deterioration of ecologically fragile areas. The most marked changes in the location were seen with the degradation of the ecological environment. Between 2000 and 2015, the geographic centre of the area under forest land to the northeast, marking the advancement of urbanization upstream. The geographic centre of grassland moved to the west. The reason may be that the degradation of forest land into grassland and of other types of land into bare land, and thus the degradation of the ecological environment in the lower reaches of the river basin.

(4) The overall correlation between temperature and the NDVI was weak, the area that showed positive correlation being larger than that which showed negative correlation. The correlation between precipitation and the NDVI was generally positive except in the eastern mountainous areas and in water bodies, where precipitation was negatively correlated to the NDVI. This indicates that the impact of precipitation on vegetation was greater than that of temperature. Vegetation was more sensitive to precipitation than to temperature. Because low temperature results in less accumulated values, the fluctuation of temperature has little effect on vegetation. The fluctuation of precipitation is greater on grassland than on forest.

(5) The correlation between changes in the NDVI and those in the population or GDP was negative, indicating the adverse effects of socio-economic development of a region on its ecological environment. The reason may be that the growth of economic and population need more water, which takes up ecological water. This leads to the degradation of ecological environment.

Paucity of the required data for the Aral Sea basin was a major obstacle to the present research, making the conclusions somewhat tentative. Therefore, improving the quality and quantity of the relevant data for the Aral Sea basin and increasing the present knowledge about the degradation of vegetation in the region should be the priorities for future research on the topic.

\section{Acknowledgments}

This work was supported by the International Science and Technology Cooperation Project of Sichuan (2020YFH0067), and the China Academy of Sciences Strategic Leading Science and Technology Project (XDA20060303).

\section{References}

[1] Liu H. L. et al. Effect of climate change on the vulnerability of a socio-ecological system in an arid area. Global and Planetary Change 137, 1-9. https://doi.org/10.1016/j.gloplacha.2015.12.014 (2016).

[2] Haeder, D. P.\& Barnes, P. W. Comparing the impacts of climate change on the responses and linkages between terrestrial and aquatic ecosystems. Science of the Total Environment 682, 39-246. https://doi.org/10.1016/j.scitotenv.2019.05.024 (2019).

[3] Manaut, N. et al. Potentialities of ecological engineering strategy based on native arbuscular mycorrhizal community for improving afforestation programs with carob trees in degraded environments. Ecological Engineering 79, 113-119. https://doi.org/10.1016/j.ecoleng.2015.03.007 (2015).

[4] Barros, V. \& Stocker, T. F. Managing the risks of extreme events and disasters to advance climate change adaptation, special report of the intergovernmental panel on climate change. Journal of Clinical Endocrinology and Metabolism 18, 586-599 (2012).

[5] Xu, W. \& Su, X. Challenges and impacts of climate change and human activities on groundwaterdependent ecosystems in arid areas - a case study of the nalenggele alluvial fan in nw china. Journal of Hydrology 573, 376-385. https://doi.org/10.1016/j.jhydrol.2019.03.082 (2019).

[6] Tian Q. \& Min X. Advances in study on vegetation indices. Advances in Earth Science 13, 327-333 (1998).

[7] Suo Y. et al. Relationship between NDVI and precipitation and temperature in Middle Asia during 1982-2002. Resources Science 318, 14221429 (2009).

[8] Gessner U. et al. The relationship between precipitation anomalies and satellite-derived vegetation activity in Central Asia. Global and Planetary Change 110, 74-87. https://doi.org/10.1016/j.gloplacha.2012.09.007 (2013).

[9] Deng H. et al. Climate change with elevation and its potential impact on water resources in the Tianshan Mountains, Central Asia. Global and Planetary Change 135, 28-37. https://doi.org/10.1016/j.gloplacha.2015.09.015 (2015).

[10] Morris B. L. et al. Assessing the extent of induced leakage to an urban aquifer using environmental tracers, An example from Bishkek, capital of Kyrgyzstan, Central Asia. Hydrogeology Journal 14, 225-243. https://doi.org/10.1007/s10040-0050441-x (2006).

[11] Karthe, D., Chalov, S.\& Borchardt, D. Water resources and their management in central asia in the early 21 st century, status, challenges and future prospects. Environmental Earth Sciences 73, 487499 (2014). 
[12] Nezlin, N. P., Kostianoy, A. G.\& Li, B. L. Interannual variability and interaction of remote-sensed vegetation index and atmospheric precipitation in the aral sea region. Journal of Arid Environments 62 , 677-700. https://doi.org/10.1016/j.jaridenv.2005.01.015 (2005).

[13] Liu, Y. et al. Assessing the effects of climate variation and human activities on grassland degradation and restoration across the globe. Ecological Indicators 106, 1-12. https://doi.org/10.1016/j.ecolind.2019.105504 (2019).

[14] Yang P.\& Chen Y. An analysis of terrestrial water storage variations from GRACE and GLDAS, The Tianshan Mountains and its adjacent areas, central Asia. Quaternary International 358, 106-112. https://doi.org/10.1016/j.quaint.2014.09.077 (2015).

[15] Deng M. et al. An analysis of the exploitation cooperation and problems of transboundary water resources in the five Central Asian countries. Advances in Earth Sciences 25, 1337-1346 (2010).

[16] Luo G. et al. Influence mechanism of landscape structure in River Ili delta. Arid Land Geography 356, 897-908 (2012).

[17] Luo G. et al. Dynamics of landscape patterns in an inland river delta of Central Asia based on a cellular automata-Markov model. Regional Environmental Change 152, 277-289 (2015).

[18] Crosa G. et al. Spatial and seasonal variations in the water quality of the Amu Darya River Central Asia. Water Research 40, 2237-2245. https://doi.org/10.1016/j.watres.2006.04.004 (2006).

[19] Kriegel D. et al. Changes in glacierisation, climate and runoff in the second half of the 20th century in the Naryn basin, Central Asia. Global and Planetary Change 110, 51-61. https://doi.org/10.1016/j.gloplacha.2013.05.014 (2013).

[20] Bai J. et al. Changes in the area of inland lakes in arid regions of Central Asia during the past 30 years. Environmental Monitoring and Assessment 178, 247-256 (2011).

[21] Qiao, Q. et al. Late cenozoic evolution in the pamir-tian shan convergence, new chronological constraints from the magnetostratigraphic record of the southwestern tianshan foreland basin (ulugqat area). Tectonophysics 717, 51-64. https://doi.org/10.1016/j.tecto.2017.07.013 (2017).

[22] Kristen W. \& Ricardo S. Rainfall, groundwater, and surface water isotope data from extreme tropical cyclones (2016-2019) within the caribbean sea and atlantic ocean basins. Data in Brief 30, 1-9. https://doi.org/10.1016/j.dib.2020.105633 (2020).

[23] Ruan H. \& Yu J. Changes in land cover and evapotranspiration in the five Central Asian countries from 1992 to 2015. Acta Geographica Sinica 74, 1292 -1304 (2019). (In Chinese)

[24] Li M. et al. Assessing rates of forest change and fragmentation in Alabama, USA, using the vegetation change tracker model. Forest Ecology and Management 257, 1480-1488. https://doi.org/10.1016/j.foreco.2008.12.023 (2009).

[25] Wang, S. Y., Liu, J. S. \& Ma, T. B. Dynamics and changes in spatial patterns of land use in yellow river basin, china. Land Use Policy 27, 313-323. https://doi.org/10.1016/j.landusepol.2009.04.002 (2010).

[26] Han L. et al. A modified transfer matrix method for the study of the bending vibration band structure in phononic crystal euler beams. Physica B Condensed Matter 407, 4579-4583. https://doi.org/10.1016/j.physb.2012.08.022 (2012).

[27] Kang Y., Liu S. \& Liu J. Image reconstruction algorithm for electrical capacitance tomography based on data correlation analysis. Flow Measurement and Instrumentation 62, 113-122. https://doi.org/10.1016/j.flowmeasinst.2018.05.006 (2018).

[28] Sun H. \& Furbish D. J. Annual precipitation and river discharges in Florida in response to El Niñoand La Niña-sea surface temperature anomalies. Journal of Hydrology 199, 74-87. https://doi.org/10.1016/S0022-1694(96)03303-3 (1997). 